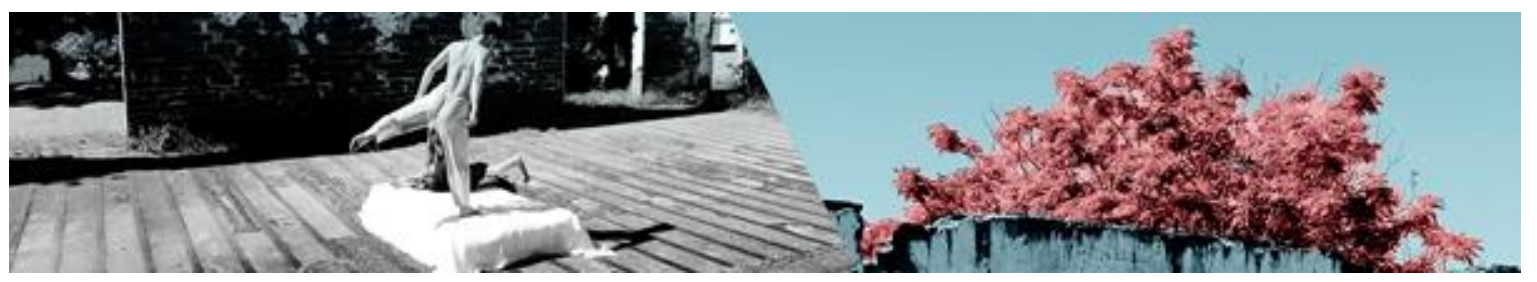

\title{
HABITAR E PULSAR: A INTEGRAÇÃO DO SER NO MUNDO É DANÇA
}

\author{
Larissa Canelhas ${ }^{1}$ \\ Kátia Salib Deffaci
}

\begin{abstract}
Resumo: Este artigo relata o processo de criação da obra de dança intitulada Habitar e Pulsar: A Integração do Ser no Mundo é Dança. A metodologia da pesquisa acontece com a prática das abordagens somáticas de movimento e também com os estudos fenomenológicos de Bachelard(1999), que descreve a integração do ser no mundo através da imagem da casa, sendo ela em três bases: Porão, Térreo e Sótão. Os estudos fenomenológicos propiciaram a poética, e o estudo do movimento nas abordagens somáticas proporcionou o ato da criação de uma obra de dança, embasada e vivida com o corpo, legitimando o processo de se construir conhecimento. O resultado foi a prática da pesquisa como confirmação potente dos estudos somáticos e da criação em dança como um espaço de múltiplos saberes.
\end{abstract}

Palavras-chave: Criação em Dança; Educação Somática; Fenomenologia.

\section{DWELLING AND PULSATING: THE INTEGRATION OF BEING IN THE WORLD IS DANCE}

Abstract: This article is based on the creation of the dance work titled Habitar e Pulsar: The Integration of Being in the World is Dance. The methodology of the visit happens with the somatic approaches to movement and the phenomenological studies of Bachelard (1999), which describe the nature of the house, being in three bases: basement, basement and attic. It was identified that such studies provided a poetic, and, the study of the movement provided the act of creating a dance work, the basement and the experience with the body, legitimizing the process of building knowledge. The result was a practice of research on the space of somatic studies and creation in dance as a space of multiple knowledges.

Keywords: Creative Process; Somatic Education; Phenomenology.

\section{Soma Investigativa}

Este artigo relata o processo da Prática como Pesquisa (FERNANDES, 2015) ocorrida na Graduação em Dança da Universidade Estadual do Rio Grande do Sul. .

\footnotetext{
${ }^{1}$ Larissa Canelhas é graduada em Dança: Licenciatura pela Universidade Estadual do Rio Grande do Sul/ UERGS. Foi Bolsista pelo Programa Institucional de Bolsas de Iniciação a Docência. Participou da Residência Artística "Do perigo de se contar uma única história" do Projeto: "Espaços Sobre as Pequenas Distâncias. Estudos para o Infinito" no Centro de Referência da Dança de São Paulo. É integrante do Coletivo Órbita onde atua como bailarina intérprete criadora e professora.

2 Kátia Salib Deffaci é professora da Graduação em Dança: Licenciatura da Universidade Estadual do Rio Grande do Sul/ UERGS. É bacharel e licenciada em Dança pela Universidade Estadual de Campinas/UNICAMP e Mestre em Artes Cênicas pelo Programa de Pós Graduação em Artes Cênicas da Universidade Federal do Rio Grande do Sul/UFRGS. Doutoranda em Educação na Universidade Estadual de Campinas/UNICAMP. Exerceu docência em Arte na Educação Básica na rede pública e particular; e ministrou oficinas de dança para bailarinos e atores. Pesquisa processos de criação, educação somática, educação infantil e cultura popular brasileira.
} 


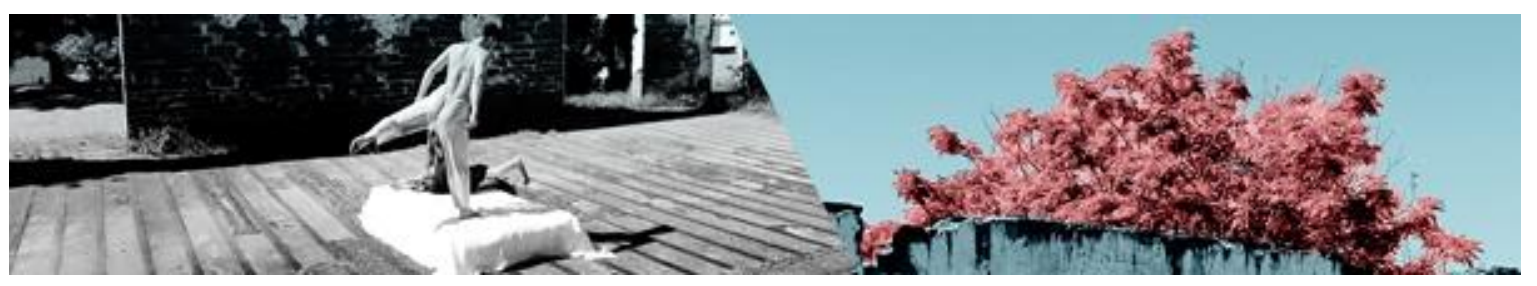

O processo de criação em dança foi proposto a partir das abordagens somáticas de movimento ${ }^{3}$ em conexão com a fenomenologia da imagem da casa discorrida por Bachelard(1999). Segundo a pesquisa conduzida pela perspectiva da Prática, a poética fenomenológica traz imagens que dialogam com a linguagem da dança nas abordagens somáticas. Assim, o objetivo foi que o sujeito soma pudesse habitar/pulsar/ser dança no palco de sua própria análise, adquirindo a integração a partir de seu desenvolvimento em busca da união entre cognição-sensação-intuição.

Sobre as abordagens somáticas o processo de criação teve a condução a partir do Sistema Laban/Bartenieff (FERNANDES, 2006; LAMBERT, 2010), que é um sistema aberto, de múltiplas e variadas aplicações e a principal referência para a prática dessa criação. Irmgard Bartenieff desenvolveu os Fundamentos Corporais (Bartenieff Fundamentals TM) que atualmente são aprofundados e difundidos através do Laban/Bartenieff Institute of Movement Studies- LIMS em um sistema que propõe quatro categorias: Corpo, Expressividade, Espaço e Forma (FERNANDES, 2006). Bartenieff foi discípula de Rudolf von Laban, um dos pioneiros no desenvolvimento da dança-teatro (tanztheater). Seu trabalho com a dança delineou uma linguagem para o movimento corporal com aplicações teóricas, coreográficas, educativas e terapêuticas (FERNANDES, 2006).

A fenomenologia é uma vertente da filosofia que busca descrever o fenômeno das coisas em sua origem perceptiva, uma corrente que surge com o filósofo Edmund Husserl e torna-se importante na reflexão de outras áreas de conhecimento. Logo, por se tratar da percepção e sua fonte (corpo), a construção dessa pesquisa, foi influenciada pela abordagem filosófico-fenomenológica da existência do ser, e contribuiu para dar sentido à poética do trabalho.

A referência para a investigação poética foi a obra "A Poética do Espaço" (BACHELARD, 1999) que discorre sobre a fenomenologia da imaginação ou do devaneio e escreve sobre o espaço simbólico da casa como uma imagem que,

${ }^{3}$ Campo do saber do corpo ou soma, em sua origem epistemológica e histórica, um conhecimento holístico, ou seja, processo que integra, associa as estruturas, investiga a função.(FORTIN, 2011, p. 27).

CANELHAS, Larissa. DEFFACI, Kátia Salib. Habitar e pulsar: a integração do ser no mundo é dança. Revista da FUNDARTE, Montenegro, p.359-373, ano 19, ํㅜ 37, Janeiro/Março.

Disponível em: http://.seer.fundarte.rs.gov.br/index.php/RevistadaFundarte/index> 30 de março de 2019. 


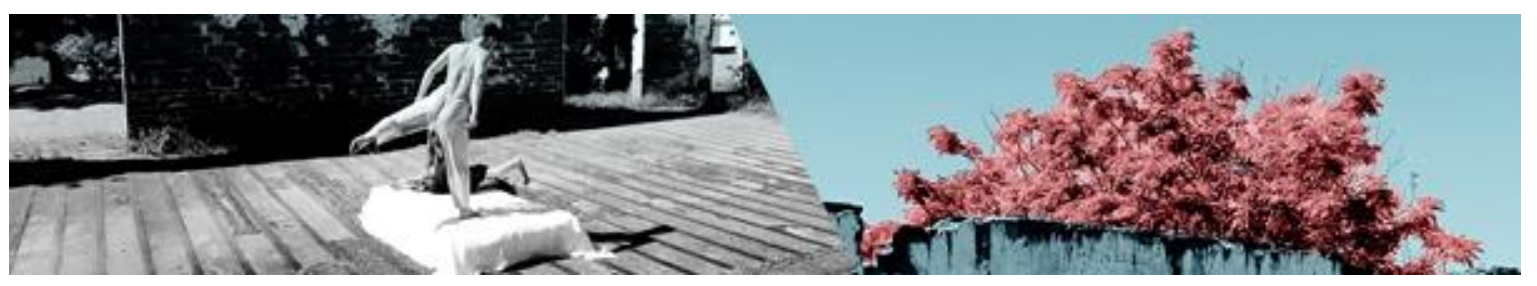

poeticamente, evoca o sentido do ser que se integra ao mundo. A integração do ser é tratada na poética da imagem através dos níveis da casa, sendo eles: Porão, Térreo e Sótão. Utilizei, portanto, nessa pesquisa, tais imagens e suas características para relacionar aos processos somáticos do Sistema Laban/Bartenieff, ou seja, uma analogia entre procedimentos do Sistema e os níveis da casa foram aprofundadas como metodologia para a criação em dança, destacando o aprendizado e a confirmação da potência da dança com outras áreas do conhecimento.

A educação somática e a fenomenologia foram tratadas nessa pesquisa como um ato político, disposto pelo atravessamento da Graduação em Dança. Portanto, iniciei uma busca filosófica existencial apoiada em Bachelard (1999) e desenvolvi a minha dança como um ato performativo e somático (FERNANDES, 2015) dessa investigação.

\section{Processo de Criação}

No processo de criação com a imagem da casa, surgiu a poética do feminino, também investigada através do Porão, Térreo e Sótão. A incorporação da dança a esses espaços foram gestados com a finalidade de repensar e reinventar a existência.

Quanto ao elenco, pude contar com a presença de mais duas bailarinasintérpretes durante parte do processo: Camila $\mathrm{Pasa}^{4}$ e Amanda Bianca ${ }^{5}$ Para descrever esse processo, irei citar os espaços da casa e as suas respectivas descrições segundo os estudos fenomenológicos; e, ainda, mostrar como o Sistema Laban/Bartennief norteou o estado de corpo, a poética e a criação em dança.

\subsection{Porão}

${ }^{4}$ Graduada em Teatro: Licenciatura pela Universidade Estadual do Rio Grande do Sul e graduanda em Dança: Licenciatura pela mesma. Atua como colaboradora do Coletivo Órbita.

5 Graduada em Dança: Licenciatura pela Universidade Estadual do Rio Grande do Sul. Atua como colaboradora do Coletivo Órbita

CANELHAS, Larissa. DEFFACI, Kátia Salib. Habitar e pulsar: a integração do ser no mundo é dança. Revista da FUNDARTE, Montenegro, p.359-373, ano 19, no 37, Janeiro/Março.

Disponível em: http://seer.fundarte.rs.gov.br/index.php/RevistadaFundarte/index> 30 de março de 2019. 


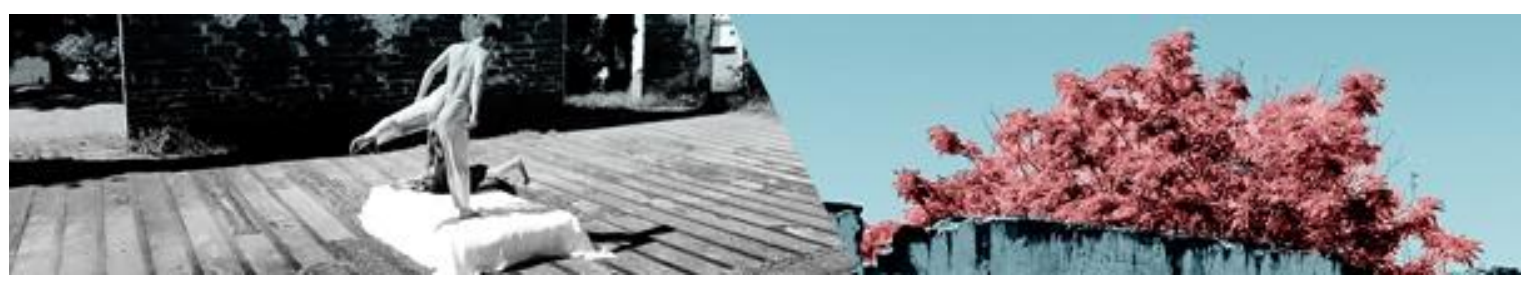

O Porão, dentro da poética de Bachelard (1999) é interpretado como aspectos da nossa personalidade que nos sustentam e ao mesmo tempo nos ameaçam:

O porão é, pois, a loucura enterrada, dramas murados. (... ) Para o porão também encontraremos, sem dúvida, utilidade. Nós o racionalizaremos enumerando suas comodidades. Mas ele é em primeiro lugar o ser obscuro da casa, o ser que participa das potências subterrâneas. Sonhando com ele, concordamos com a irracionalidade das profundezas. (BACHELARD, 1999, p.209).

Consequentemente, associei às primeiras experiências do ser no mundo, o que nos ocorre durante o período uterino e nos primeiros anos, o que atravessa 0 corpo ainda em desenvolvimento. Tal associação foi experimentada na criação com o foco na percepção e ação, em consonância com a Categoria Corpo no Sistema Laban/Bartenieff. Nesse Sistema, dentro da categoria Corpo, organizam-se os Padrões Neurológicos Básicos(PNB), que são as etapas de movimento neuromusculares que ocorrem nos primeiros meses de vida, sendo eles: Respiração Celular, Irradiação Central, Espinhal, Homólogo, Homolateral e Contralateral (Fernandes, 2006).

Tais elementos perceptivos/motores constituem as primeiras manifestações de vida, por isso as utilizei como metodologia de criação do porão, onde o elo percepção/ação estabelece os mecanismos/padrões que irão acompanhar o indivíduo ao longo de sua vida, como aponta Lambert (2010, p.52):

\begin{abstract}
Esse aprendizado de base ata-se à evolução da habilidade motora em integração com 0 amadurecimento perceptivo/sensorial, emocional e cognitivo, interligando os vários aspectos da vida em um movimento dinâmico. Acompanhando os dizeres da própria evolução do ser humano, esse processo neurocinesiológico desenrola-se de forma inconsciente durante o primeiro ano de vida, estabelecendo um patamar inicial de eficiências ou restrições perceptivo-motoras.
\end{abstract}

CANELHAS, Larissa. DEFFACI, Kátia Salib. Habitar e pulsar: a integração do ser no mundo é dança. Revista da FUNDARTE, Montenegro, p.359-373, ano 19, ํㅡ 37, Janeiro/Março.

Disponível em: http://.seer.fundarte.rs.gov.br/index.php/RevistadaFundarte/index> 30 de março de 2019. 


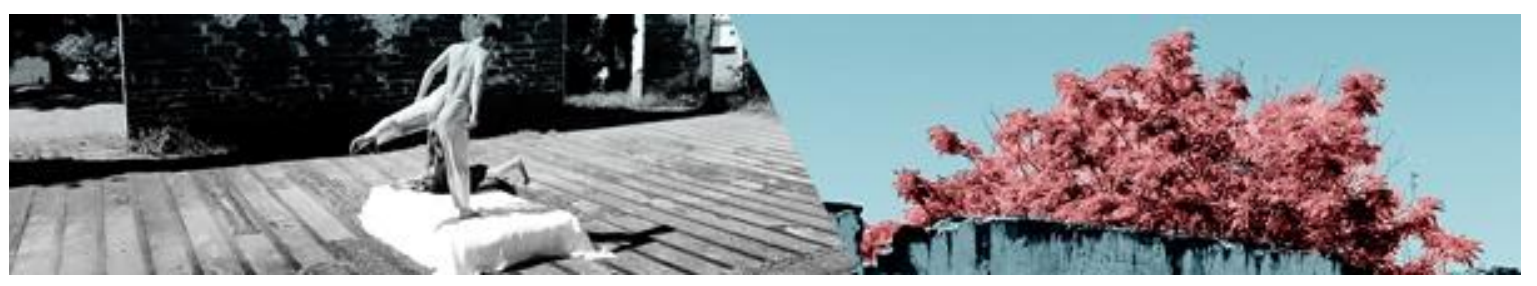

Essa categoria foi aprofundada em experimentações que resultaram em qualidades de movimento denominadas, segundo o Sistema Laban/Bartenieff, como Estados Expressivos ${ }^{6}$, que fazem parte da categoria Expressividade.

Os ensaios do Porão ocorreram em diversos locais e foi possível perceber que há influências desses locais na criação. No primeiro local, que era de fato um porão, frio e úmido, de teto baixo, as movimentações surgiram lentas e em contato com o chão. Já no segundo local, a composição corporal de figuras, com características de torções e valorização de ângulos do espaço, surgiram a partir de uma extensa e alta sala de ensaio com janelas que possuíam vista para um parque. E, por fim, no terceiro local de ensaio, a ligação de movimentos entre a bailarinas foi trabalhado em uma casa comunitária que atendia as demandas sociais da comunidade.

Assim, elaborei essa etapa ao meu próprio modo "porão" de ser. Vasculhei as memórias e os espaços da casa, onde fui tomada na infância e, como tal, poderiam me trazer o chão firme para pisar no térreo. Analisei aspectos da minha personalidade, que são notáveis por pessoas da minha convivência, mas não por mim; e também as singularidades no meu modo específico de demonstrar emoções nas relações afetivas, que podem ser associados ao momento da minha vida, sob a gestação no corpo de minha mãe.

O período uterino, momento em que deveria prevalecer a segurança necessária para o desenvolvimento de uma nova vida, foi, para mim, busca por sobrevivência. Abordo aqui este contexto para dar ênfase no processo de pesquisa, pois encontrar a simbologia da casa para explicar a percepção e atuação humana no mundo me fez ter a vontade de investigar dançando, um estado de se perceber não só como um corpo qualquer, mas como um sistema potente de movimento, linguagem, afeto e significação, criador de outros mundos/realidades possíveis através da arte.

${ }^{6}$ Refere-se à teoria e prática desenvolvidas por Laban, onde, qualidades dinâmicas se relacionam aos fatores: fluxo, espaço, peso e tempo, associando-os em pares.

CANELHAS, Larissa. DEFFACI, Kátia Salib. Habitar e pulsar: a integração do ser no mundo é dança. Revista da FUNDARTE, Montenegro, p.359-373, ano 19, no 37, Janeiro/Março.

Disponível em: http://.seer.fundarte.rs.gov.br/index.php/RevistadaFundarte/index> 30 de março de 2019. 


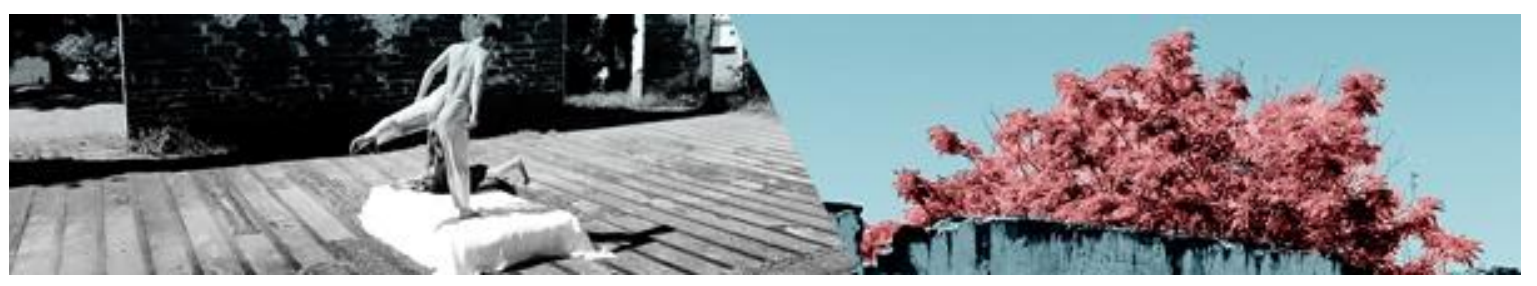

Assim, nessa fase da pesquisa, analisando o meu próprio porão e a construção da cena, bem como o desenvolvimento poético dos corpos pesquisadores, fica notável como se estabeleceu o contato com o chão, apoiado no aprendizado do corpo antes de chegar à verticalidade. Além disso, é notável como esse contato estabeleceu as primeiras conexões percorridas a partir da ligação do centro do corpo com a suas periferias, e do uso das lateralidades em conexão homolateral, desenho no espaço que era imaginado antes do movimento, já que:

Imaginar o percurso que as partes do corpo vão seguir no espaço cria um propósito externo claro, abre caminhos internos no corpo que organizam padrões de resposta motora, direcionando a energia cinética para preencher a intenção desejada. (LAMBERT,2010, p.112).

Assim, habitar o espaço e as propostas vividas levou-me até a construção de figuras, que nesse processo são entendidas como a fixação de determinados movimentos/posturas. Foi criada uma relação entre bailarinas, espaço e corpos, como se houvesse um fio invisível nas articulações ósseas que reverberava em uma composição de variações posturais. Referente a esse processo, Lambert (2010, p.50) aponta que:

Ao reconhecer a sua origem no espaço entre o fora e o dentro, a dança abraçou os processos neurológicos, orgânicos e afetivos como elementos construtores do percurso cinético do corpo no espaço, alargando a compreensão da experiência criativa pela comunhão com o ressoar vibrante dos ritmos da interioridade.

A minha associação com o feminino, que particularmente investigava pensando na continuação com a ligação do período uterino, ocorreu na Casa Comunitária ${ }^{7}$, que se trata de um lugar/não lugar/utopia, e que faz presente no ato miúdo de se poder compartilhar. Confirmou-se, portanto, minha associação com o

7 O Espaço Comunitário, também conhecido como o gabinete do Partido dos Trabalhadores, possui em seus fundos uma horta criada pelos seus habitantes itinerantes, onde almoços são oferecidos a preço de custo. Ou seja, encontro nesse espaço mais símbolos do feminino que me atravessam: nutrição, como a mãe que nos amamenta quando ainda somos muito pequenos, e a resistência da arte e da licenciatura no Estado por atender demandas dos universitários e da comunidade.

CANELHAS, Larissa. DEFFACI, Kátia Salib. Habitar e pulsar: a integração do ser no mundo é dança. Revista da FUNDARTE, Montenegro, p.359-373, ano 19, ํㅡ 37, Janeiro/Março.

Disponível em: http://.seer.fundarte.rs.gov.br/index.php/RevistadaFundarte/index> 30 de março de 2019. 


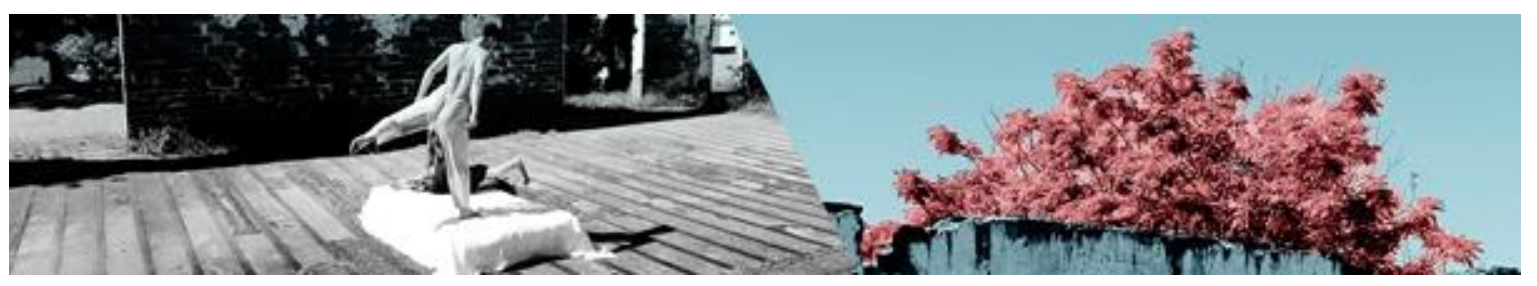

feminino na criação. O primeiro espaço que habitamos enquanto seres também foi compartilhado: o útero/ventre/entranhas de uma mulher que se transformava em mãe, seguindo nesse processo, o cordão umbilical foi matéria que me (nos) ligou profundamente a uma mulher, e é também uma cicatriz de separação. Achei isso significativo para a cena/pesquisa do porão, já que ele é como o portal das nossas percepções no mundo. Assim, levei para essa criação um longo tecido branco para conectar as movimentações entre eu e as demais bailarinas, como se fosse a profunda ligação que todos os seres humanos possuem com o útero.

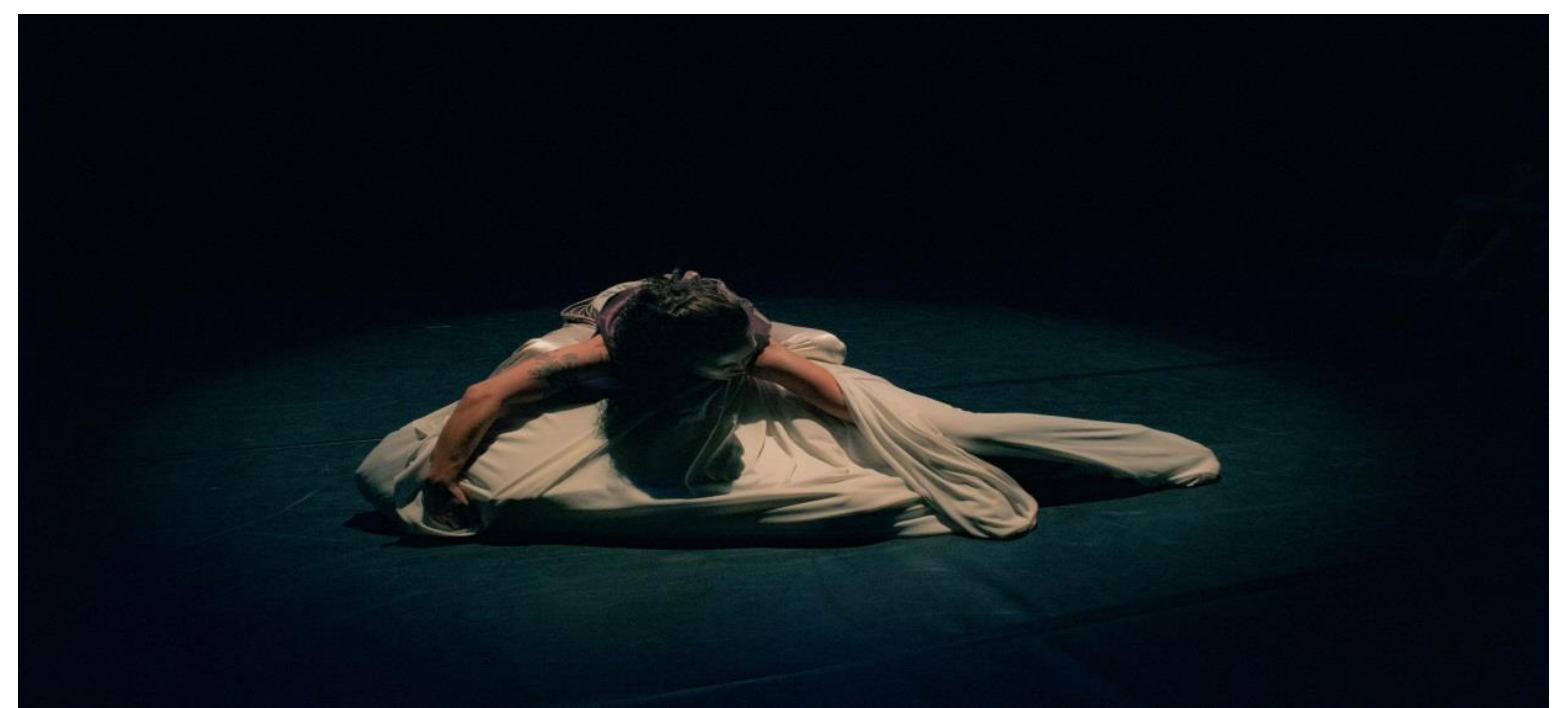

Figura 1: Porão. Apresentação final. Foto: Victória Sanguiné, 2019

A ligação do tecido amarrado em nossos ventres era a linha tênue entre as duas oposições da existência: certeza da vida e medo da morte; peso e leveza; encolhimento e expansão; entrega e resistência.

\subsection{Térreo}

Integrando o processo corporal destes encontros com as associações poéticas acerca do feminino, segui para a etapa do Térreo, levando nos corpos as explorações de movimentos de cada espaço, e as figuras criadas em estados singulares. O Térreo foi pensado como a transição do corpo para a vertical, e foram 


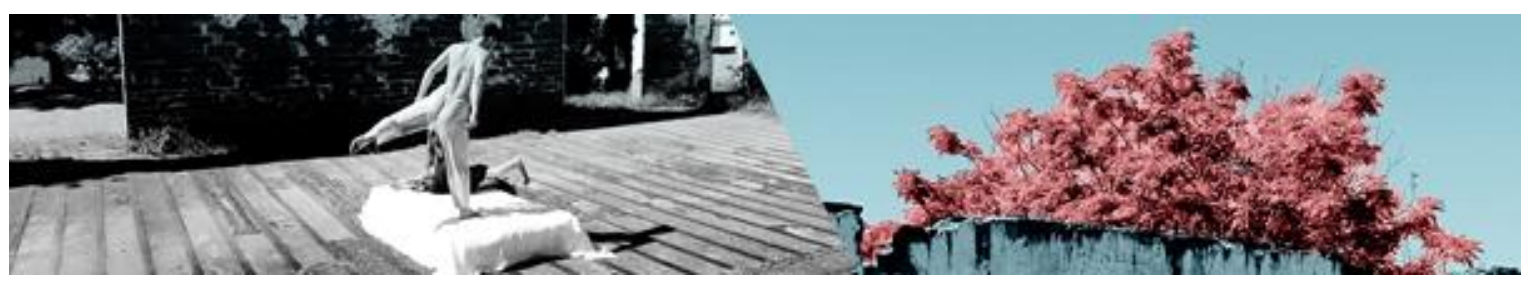

investigadas as ações/movimentações que tais figuras desenvolviam como mais uma etapa no domínio do movimento e da integração da casa no mundo.

A imaginação nesse processo é também fundamental para a definição do estado/cômodo do térreo, pois o ser que vive no porão escuro depara-se no térreo com um lugar já iluminado e, com a vista da janela, contempla a imensidão possível do devaneio e a possibilidade de se chegar ao sótão, já que "A lâmpada à janela é o olho da casa. A lâmpada na janela, no reino da imaginação, não se acende nunca ao lado de fora. É luz enclausurada que só pode filtrar do lado de fora" (Bachelard, 1999, p.219).

Estabelecemos que a influência imaginária para essa etapa estivesse relacionada com a cozinha, primeiro por ser um lugar comum entre nós, e onde a figura feminina mais se destaca dentro das nossas memórias de casas. Pensamos também que é nesse cômodo que a alquimia acontece, numa série de movimentos/ações que criam a nutrição e a manutenção dos habitantes da casa.

Nesse processo, o movimento de pulsar esteve com o domínio do corpo em um ritmo constante de movimentos, em que a respiração foi base para gerar energia, sem pausas, em busca de um estado corporal de esvaziamento, pulsante para a criação de ações das figuras criadas no porão. Neste sentido, o trabalho da respiração na criação em dança reforçou o entendimento de sua importância, pois "estimula, ainda, um estado simples de ser, sutil, contínuo e global que, em um processo de criação, pode ser relacionado com um estado de concentração, esvaziamento e gestação do ato de criação" (Lambert, 2010, p.121). E por falar em pulso, uso essa palavra como chave para o térreo. Na definição da palavra temos o verbo intransitivo como referente ao "mover com um impulso; ter percepção ou intuição; ter ou mostrar pulsação" (Priberam, 2013). Na dinâmica de integração do corpo, o Suporte de Respiração (FERNANDES, 2006) se destaca no trabalho desenvolvido por Bartenieff, denominado como Respiração Tridimensional ou Respiração Celular. Nessa análise do corpo, a iniciação é postural/pulsional devido a esse sistema de inflar e desinflar.

CANELHAS, Larissa. DEFFACI, Kátia Salib. Habitar e pulsar: a integração do ser no mundo é dança. Revista da FUNDARTE, Montenegro, p.359-373, ano 19, nำ37, Janeiro/Março.

Disponível em: http://.seer.fundarte.rs.gov.br/index.php/RevistadaFundarte/index> 30 de março de 2019. 


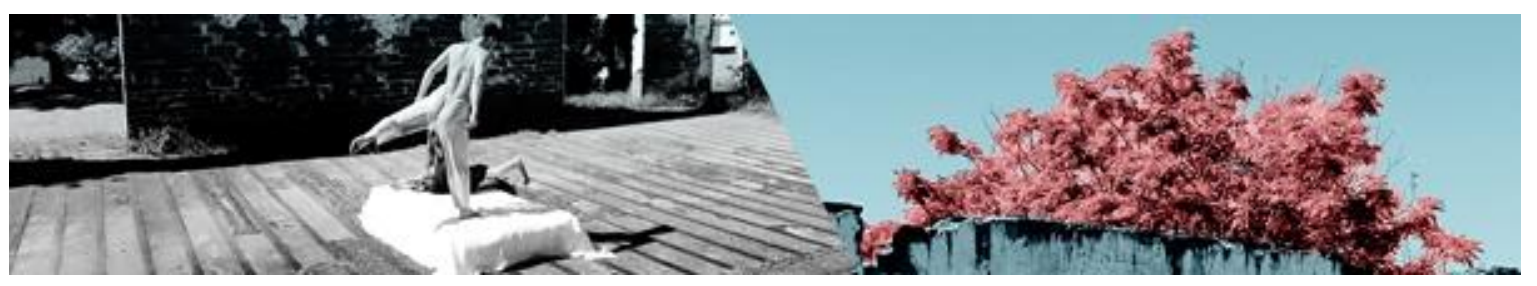

$\mathrm{Na}$ construção ou continuação das figuras criadas a partir da experiência do Porão foram aprofundadas as ações e suas respectivas qualidades, que delinearam as características corporais da dança nesse nível de integração. Como processo de criação, a categoria Expressividade do Sistema Laban/Bartennieff foi investigada:

A categoria Expressividade refere-se à teoria e prática desenvolvidas por Laban, onde qualidades dinâmicas expressam a atitude interna do indivíduo com relação a quatro fatores dispostos na ordem de seu desenvolvimento na infância (FERNANDES, 2006, p. 120).

Pensando na imagem da contemplação da imensidão do mundo, discorrida por Bachelard (1999), cada bailarina escolheu um espaço de intimidade de si e do seu cotidiano para observar como os corpos o habitavam, como se olhássemos através de uma janela, e, a partir disso, na sala de ensaio, trabalhei os quatro fatores expressivos.

A base de experimentação/manutenção/sustentação das ações é a presença do pulsar, da respiração, no ato de conduzir o corpo dentro da imaginação. Essa pulsação trouxe para as figuras singularidades que se apoiam na construção do ser no mundo, que nessa pesquisa em dança é exercida pelos fatores expressivos.

\subsection{Sótão}

Essa etapa é caracterizada na obra de Bachelard (1999) como o lugar onde o ser, já consciente do porão e iluminado pela luz do térreo, fixa sua estrutura tendo plena intimidade com a casa, conseguindo, portanto, transcender seu espaço de intimidade com o ato de sonhar, assim como cita Bachelard (1999, p.209-214):

Os andares mais altos, o sótão, o sonhador os "edifica", e os reedifica bem edificados. Com os sonhos na altitude clara estamos, repitamo-lo, na zona racional dos projetos intelectualizados.

[...]Enfim, a escada do sótão mais abrupta, mais gasta, nós a subimos sempre. Há o sinal de subida para a mais tranquila solidão. Quando volto a sonhar nos sótãos de outrora, não desço mais.

CANELHAS, Larissa. DEFFACI, Kátia Salib. Habitar e pulsar: a integração do ser no mundo é dança. Revista da FUNDARTE, Montenegro, p.359-373, ano 19, ํㅡ 37, Janeiro/Março.

Disponível em: http://.seer.fundarte.rs.gov.br/index.php/RevistadaFundarte/index> 30 de março de 2019. 


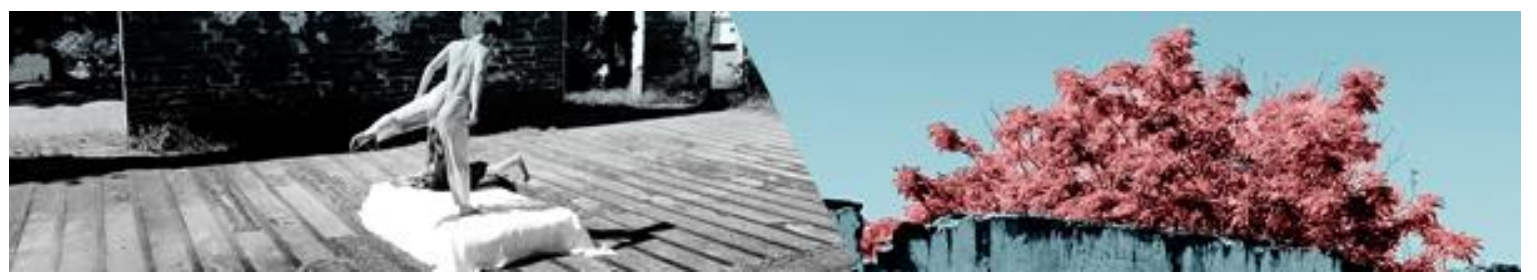

Ciane Fernandes afirma que as teorias de movimento do Laban baseiam se nas relações entre as polaridades e os "Temas de contínua dinâmica e transformação" (FERNANDES, 2006, p.265). Segundo Fernandes (2006), as dimensões postas entre interno e externo relacionam-se constantemente e dizem respeito ao que há dentro do corpo, desde sensações até experiências pessoais que deixam registro nesse espaço e fora dele, como o meio ambiente, as pessoas e os acontecimentos. Compreendi, nessa etapa da pesquisa, que o Sótão, enquanto imagem da casa integrada, ocorreria na interação entre interior e exterior.

A pesquisa foi feita da sala de ensaio para a rua, e o ato de habitar esse espaço com as figuras implicou na escuta do corpo em deslocamentos amplos e contínuos: manter a figura ao atravessar a rua, olhar para outros corpos enquanto sentíamos as tensões que as figuras causavam e, principalmente, o olhar dos transeuntes sobre as figuras, ou o desvio do olhar, o que aumentou a vontade de romper com os limites que o palco delimita com o público.

A organização corporal modificou-se ao chão de asfalto desnivelado, e os bancos da praça, a terra, as folhas e a vista tornaram a investigação que anteriormente era interna, para externa. As pessoas que me olharam e que por mim foram observadas fizeram com que explorasse gestualidades além das que já tinha.

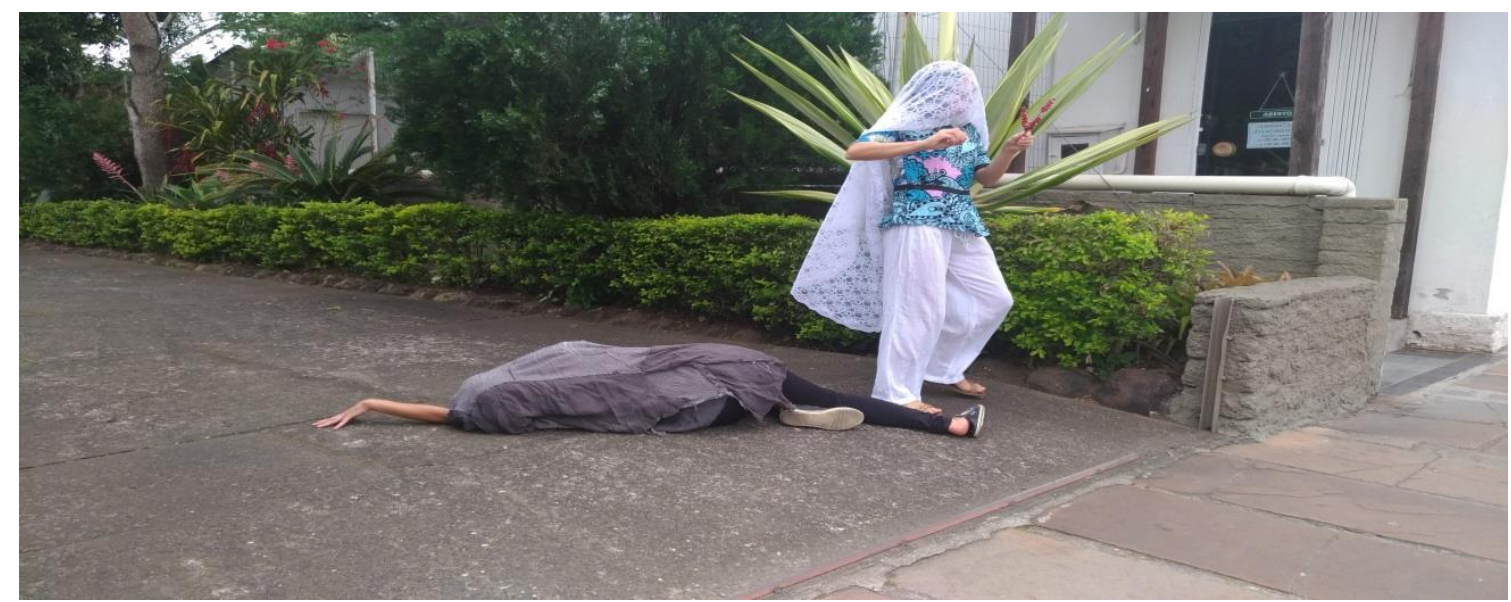

Figura 2: Saída para a rua durante o ensaio. Foto: Lau Graef, 2019.

CANELHAS, Larissa. DEFFACI, Kátia Salib. Habitar e pulsar: a integração do ser no mundo é dança. Revista da FUNDARTE, Montenegro, p.359-373, ano 19, nำ37, Janeiro/Março.

Disponível em: http://.seer.fundarte.rs.gov.br/index.php/RevistadaFundarte/index> 30 de março de 2019. 


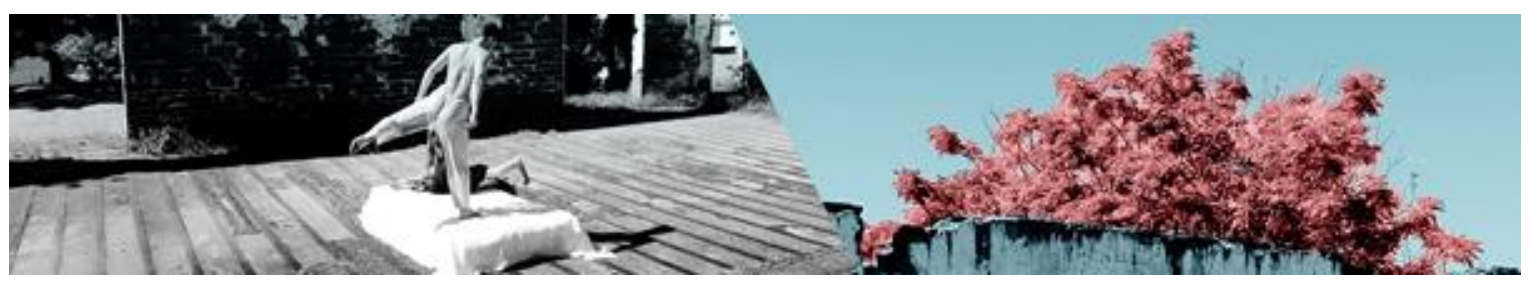

Após essa vivência na rua, o processo de criação voltou para a sala de ensaio, e os movimentos foram repetidos enquanto eram visualizados, e assim transformados a partir das percepções e sensações. Nesse sentido, entendo o corpo do artista como um agente de transformação, que precisa do externo para modificar o meio em que está. Também, Fernandes (2006, p.371) aponta que:

O corpo, hoje mais do que nunca, é um representante do self, uma mensagem da identidade pessoal, "uma ilha de segurança em um sistema global [complexo e incontrolável], caracterizado por riscos múltiplos e inescapáveis [...], que tem como característica principal a efemeridade; é um fenômeno biológico e social não acabado e em transformação através da interação com o meio.

A transformação das ações vivenciadas nas ruas foi baseada no tema de Esforço e Recuperação, onde determinadas qualidades de movimento são utilizadas em uma composição entre o agir - o Esforço com determinadas características, que em seguida a movimentação confere um contraponto às qualidades utilizadas- e a Recuperação, criando um ritmo e uma sequência (FERNANDES, 2006, p. 266).

Após essa experiência, estando Camila e eu habitando a pesquisa e no estado de amarração dramatúrgica do que existia até então, compreendi que o sótão ocorreu quando as figuras foram para a rua, quando o que era trabalhado internamente em sala de ensaio é integrado ao espaço exterior a ela.

O elemento estético que inaugura o sótão em cena é a descida de uma janela redonda, como imagem proposta pelo autor ao descrevê-la com a luz que observa de dentro. Instaura-se na casa o sentido da vista, e, portanto, a confirmação de sua integração ao mundo: redonda simbolicamente pela relação circundante entre dentro e fora, segundo Bachelard(1999, p. 215-232):

Diríamos então que: "Das Dasein it rund", o ser é redondo. Pois acrescentar que parece é conservar uma dicotomia entre o ser e a aparência, quando na verdade o que se quer dizer é todo o ser em sua redondeza. [...]Mais uma vez, as imagens da redondeza plena ajudam a nos congregarmos em nós mesmos, a darmos a nós mesmos uma primeira constituição, a afirmar o nosso ser intimamente, pelo interior. Pois, vivido do interior sem exterioridade, o ser não poderia deixar de ser redondo.

CANELHAS, Larissa. DEFFACI, Kátia Salib. Habitar e pulsar: a integração do ser no mundo é dança. Revista da FUNDARTE, Montenegro, p.359-373, ano 19, nำ37, Janeiro/Março.

Disponível em: http://.seer.fundarte.rs.gov.br/index.php/RevistadaFundarte/index> 30 de março de 2019. 


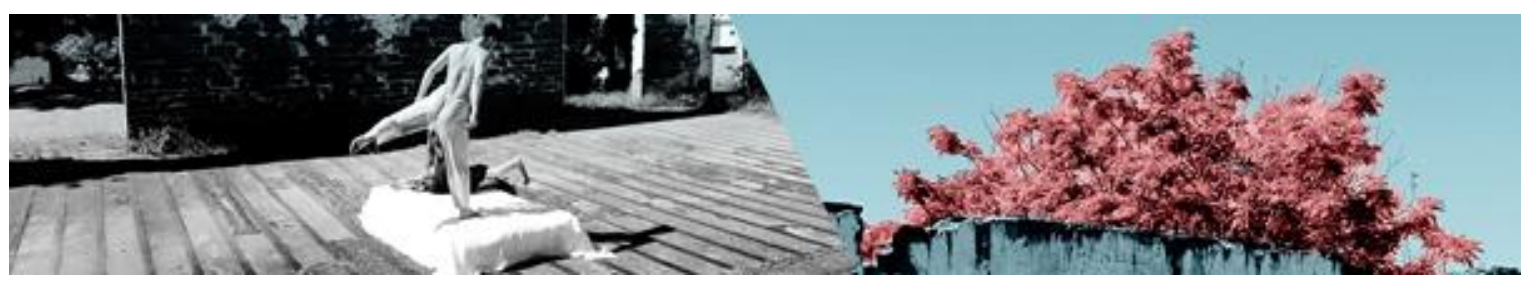

Desta maneira, a janela redonda instaura o momento de integração do espaço às figuras. No espaço externo, na rua, Camila e eu estabelecemos uma movimentação de observar a praça, o público e os seus movimentos através dessa janela, e, ao mesmo tempo, de utilizar diferentes combinações de qualidades de movimentos para integrá-los ao nosso repertório, como figuras que estão sendo integrados ao espaço presente e pulsante da cena.

Nesse sentido, estabeleci relação com o conceito da Cinesfera, que "[...] refere-se ao espaço físico tridimensional ao redor do corpo, alcançável ao estenderse sem que seja necessário transferir seu peso" (FERNANDES, 2006, p. 182). A observação dos movimentos no espaço reverbera em experimentações a partir dos Estados, ao redor da Cinesfera Média e Cinesfera Pequena. Assim, tanto a circularidade da janela quanto a circularidade do corpo em relação à vista do espaço foram trabalhadas para o sótão. Assim, a integração da casa, ou seja, a integração do corpo no mundo, segue após aprender a rastejar no porão e verticalizar no térreo; passa a explorar a circularidade de si em assimilação com o mundo, o ser tornandose potência criativa.

Na última cena as figuras circulam ao redor do público enquanto exploram os movimentos integrados ao que foi observado/transformado na praça, tanto durante os ensaios quanto com o público durante a apresentação. Os Estados Expressivos que foram trabalhados durante o processo de criação são dançados na cena final, de forma que a apresentação termine com a dispersão (integração) das figuras ao espaço da praça, rompendo com o limite estabelecido pela disposição do público.

\subsection{Habitar e Pulsar: A integração do ser no mundo é dança}

A experiência investigativa da arte propõe acesso e escolha a múltiplos campos do conhecimento em uma pesquisa; através da dança tornou-se possível entender o meu corpo como o agente potente e responsável pela travessia e transformação no mundo - e a partir dele.

CANELHAS, Larissa. DEFFACI, Kátia Salib. Habitar e pulsar: a integração do ser no mundo é dança. Revista da FUNDARTE, Montenegro, p.359-373, ano 19, ํㅜ 37, Janeiro/Março.

Disponível em: http://.seer.fundarte.rs.gov.br/index.php/RevistadaFundarte/index> 30 de março de 2019. 


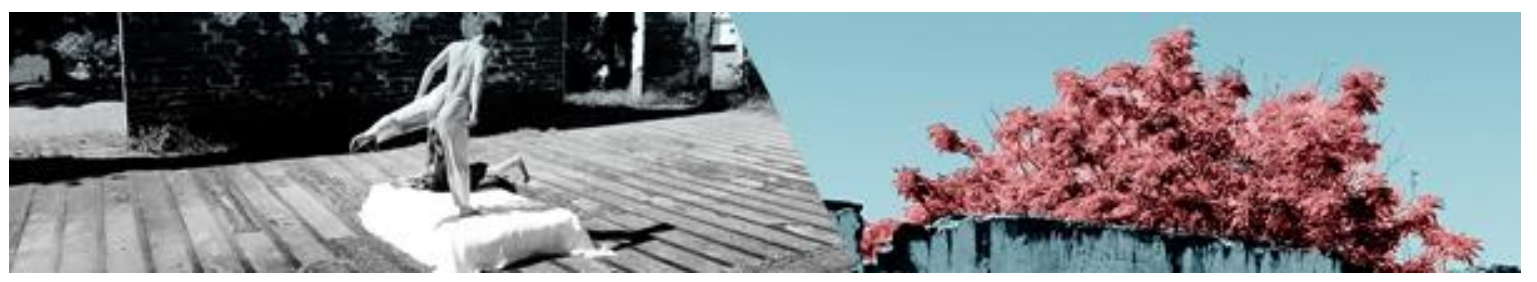

Encontrei razões e fazeres que tornaram os estudos somáticos na dança, mais uma vez, o próprio conhecimento através da sensação, da investigação sensível, da intuição como uma guia aos estudos teóricos, ao caminho de pensamento crítico que os filósofos existencialistas propõem em suas obras.

O que se estabeleceu como cena para o ato da apresentação foi apenas um recorte de descobertas tecidas em uma dramaturgia. As descobertas somáticas bailaram de dentro para fora; a estética contou sobre o corpo descoberto como morada dentro do mundo através da imagem de uma casa. Não foi intenção mostrar ao público um cenário referente a uma casa, mas, sim, deleitarmos sobre as percepções de um corpo que, dançando, integra-se processualmente ao espaço, como uma casa tem a função de abrigar.

O encontro com o Sistema Laban/Bartenieff foi o motivador dessa dança, e ficaram evidentes as múltiplas possibilidades. Nesse processo de criação, consegui relacionar e investigar as etapas de desenvolvimento motores e expressivos com as questões e memórias que me atravessam. Pude vivenciar a dança esmiuçada por esse sistema consistente e potente de afirmação do corpo humano como ser atuante do mundo.

O fato é que a dança faz pensar o ser como corpo/sistema/função, através também da sensação, e, com isso, aumenta a responsabilidade perante o mundo contemporâneo em que vivemos, já que o modo de vida instaurado atualmente ainda prioriza a razão, o pensamento lógico e concreto que se tornou mais válido do que o sentir, imaginar e intuir, e é por isso que a dança se torna um ato revolucionário de existir.

Nesse sentido vejo as técnicas e abordagens somáticas como o caminho para a dança se afirmar e consolidar, como Sastre $^{8}$ (2015, p. 107) afirma que nelas "toma-se consciência do próprio corpo pelo que se percebe dele, pela sensação,

\footnotetext{
${ }^{8}$ A autora é especialista em Laban Análise em Movimento(1999) e, como no Brasil é restrito o número de pessoas que tiveram contato com o Laban/Bartenieff Institute of Movement Studies LIMS em NY, torna-se relevante trazer suas contribuições.
} 


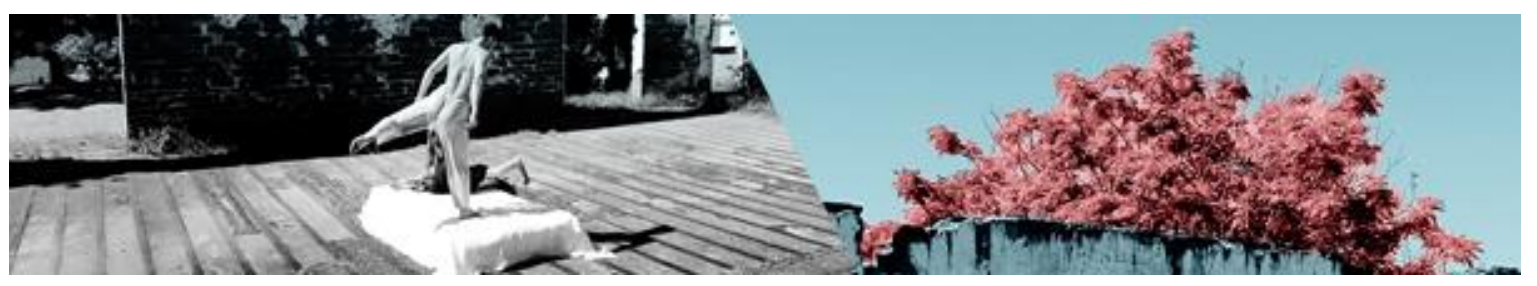

pelo que se aprende do meio ambiente, dos afetos, sistematizando a percepção de acordo com o que cada técnica proporciona".

A base dessa pesquisa esteve na busca e sentido da palavra Integração, pois, tanto na dança em questão quanto em Bachelard, o ser é estudado e discorrido a partir de sua capacidade de integrar-se ao mundo. Na dança a integração é vivida pelo ser em sua própria perspectiva proprioceptiva, e o domínio do movimento legitima esse ser enquanto parte do mundo, como Vicari ${ }^{9}$ (2013, p. 28) também afirma, nesse sentido de integração total: "a totalidade para Laban, deveria ser restabelecida através do movimento, pois está em contato com a realidade básica da existência humana, integrando arte e vida, razão e emoção, corpo e mente".

Foi possível adentrar a poética estabelecida pela imagem da casa e como pesquisadora pude descobrir em mim mesma a fenomenologia da imagem e o estudo da percepção humana. Também foi possível vivenciá-la a ponto de identificar, na minha construção enquanto ser, as manifestações de soma que me constituem, pois "o performer que traz consigo as marcas de sua historicidade, abrese para processos de criação que extrapolam a experiência artística transbordandoos pela vida" (VICARI, 2013, p. 29).

Assim, identificadas as indicações do meu modo de ser porão, pude trabalhálo artisticamente para viver o térreo, ou seja, a imaginação possibilitou que o processo corporal vivido pudesse transformar memórias em uma apresentação de dança, em uma obra de arte embasada, vivenciada com o corpo, dançada junto da experiência do movimento que inscreve e legitima o conhecimento. Assim sendo “(..) na Abordagem Somático-Performativa, a pesquisa ocorre no próprio acontecimento imprevisível, na experiência criativa total, integrando escrita e análise ao processo de imersão Corpo Ambiente" (FERNANDES, 2013, p.8).

Por fim, a sensação final perpetuou a insistência, a certeza de que a arte deve estar nas escolas e de que o acesso à dança é um privilégio que necessita ser democratizado, rompendo com limitações físicas, sendo proporcionada em diversos

\footnotetext{
${ }^{9}$ A autora também é especialista em Análise de Movimento Laban pelo Laban Bartenieff Institue of Movement Studies, Nova York (2010)
} 


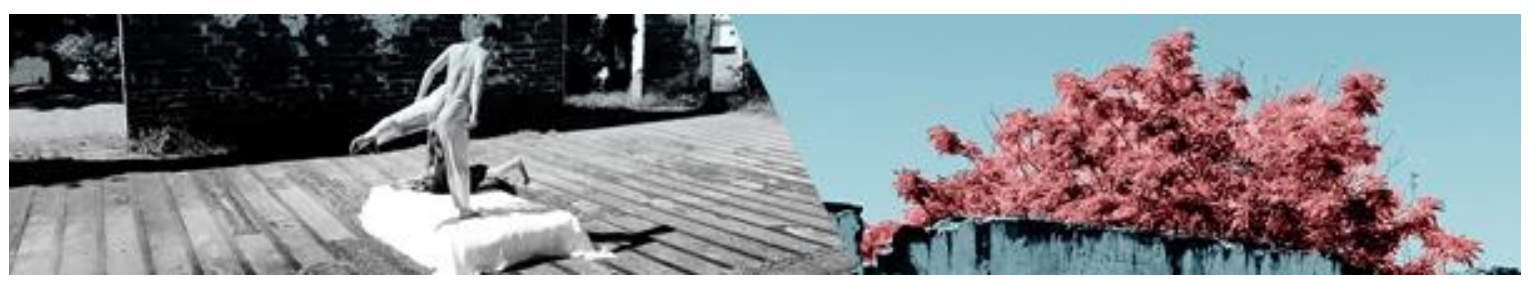

espaços: uma afirmação poderosa das possibilidades do ser humano enquanto sistema integrado dentro e fora do mundo.

\section{Referências:}

BACHELARD, Gaston. A Poética do Espaço. São Paulo: Martins Fontes,1999.

FERNANDES, In(v)ersões Corpo Ambiente e a Criação Coreo - videográfica de Uirá Meneses. Lençóis BA, 2013.

FERNANDES, Ciane. O corpo em movimento: o sistema Laban/Bartenieff na formação e pesquisa em artes cênicas. 2edição-São Paulo: Annablume, 2006.

FERNANDES, Ciane. Quando o Todo é mais que a Soma das Partes: somática como campo epistemológico contemporâneo Rev. Bras. Estud. Presença, Porto Alegre, v.5, n.1, p.9-38, jan./abr. 2015. Disponível em: < http:// www.seer.ufrgs.br/presenca $>$.

FORTIN, Sylvie. Nem do lado direito, nem do lado do avesso: o artista e suas modalidades de experiências de si e do mundo. In: WOSNICK, Cristiane; MARINHO, Nirvanna. O avesso do avesso do corpo - educação somática como práxis. Joinville: Novas Letras, 2011, p. 25-42.

LAMBERT, Marisa Martins. Expressividade Cênica pelo Fluxo Percepção/Ação: O Sistema Laban/Bartenieff no desenvolvimento somático e na criação em dança. / Marisa Martins Lambert. Tese(Doutorado) - Campinas, SP: [s.n.], 2010

PULSAR, in Dicionário Priberam da Língua Portuguesa [em linha], 2008-2013, http://www.priberam.pt/dlpo/chave [consultado em 21-10-2013].

SASTRE, Cibele. Entre o performar e o aprender: Práticas performativas, dança improvisação e análise Laban/Bartenieff em movimento.Tese(Doutorado) Universidade Federal do Rio Grande do Sul/Porto Alegre. Cibele Sastre/2015.

VICARI, Juliana. Raízes para voar: Caminhos para uma abordagem somática grouding.2013. Dissertação (Mestrado pelo Programa de Pós Graduação em Artes Cênicas) Universidade Federal do Rio Grande do Sul/ Porto Alegre-2013. 